\title{
Primo de Rivera y Portugal, 1923-1931: del "peligro español" a la nostalgia de la España autoritaria
}

\author{
Primo de Rivera and Portugal, 1923-1931: From "The Spanish \\ Danger" to Longing for Authoritarian Spain
}

\author{
Juan Carlos Jiménez Redondo \\ Universidad San Pablo CEU \\ jcjimenez.fhum@ceu.es \\ ORCID: 0000-0001-5752-5199
}

Recibido: 23-11-2016

Aceptado: 15-3-2017

Cómo citar este artículo / Citation: JIMÉNEZ REDONDO, Juan Carlos (2017). Primo de Rivera y Portugal, 1923-1931: del "peligro español" a la nostalgia de la España autoritaria. Pasado y Memoria. Revista de Historia Contemporánea, 16, pp. 91-117. https://doi.org/10.14198/PASADO2017.16.05

\section{Resumen}

El imaginario nacionalista portugués había situado a España como la gran amenaza a su independencia y soberanía nacional. Si hasta 1919 esa percepción se basó en indudables tentaciones anexionistas españolas, a partir de esa fecha la política portuguesa de España se caracterizó por el respeto y la no injerencia en los asuntos internos lusos. Primo de Rivera afianzó esta evolución con una política basada en ese ideal aliancista que el pensamiento conservador y reaccionario español y portugués estaba definiendo como base de un proyecto político e ideológico de regeneración interna e internacional, de clara tendencia autoritaria. Esta convergencia ideológica inició un cambio radical de la imagen de España en Portugal, que acabó por definirse con la definitiva imposición de las dictaduras salazarista y franquista.

Palabras clave: Dictadura de Primo de Rivera, España, Portugal, Iberismo, Nacionalismo, Siglo XX. 


\begin{abstract}
Spain had been traditionally considered by Portuguese nationalism as the greatest threat to national independence and sovereignty. While this perception derived from the old undeniable annexationist Spanish attempts, from 1919 onwards, however, Spanish policy towards Portugal was characterized by full respect and an attitude of non-interference in Portuguese internal affairs. Primo de Rivera strengthened this shift by means of the pro-alliance concept policy that Spanish and Portuguese reactionary and conservative thinking identified with the basis for a political and ideological project of domestic and international regeneration clearly authoritarian. This ideological convergence introduced a radical change in the image of Spain in Portugal which eventually defined itself through the imposed dictatorships of Franco and Salazar.
\end{abstract}

Keywords Primo de Rivera's Dictatorship, Spain, Portugal, Iberism, Nationalism, $20^{\text {th }}$ Century.

\title{
Historia e imágenes hispano-lusas: iberismo y peligro español ${ }^{1}$
}

La imagen que un país tiene de otro es un complejo proceso de construcción simbólica que responde a la confluencia de numerosos factores, entre los que destaca el concepto de confianza recíproca ${ }^{2}$. Los países tienden a imaginar a los otros desde una perspectiva muy general, configurada por un conjunto de ideas y tópicos bastante primarios, pero por ello mismo, de fácil socialización y fuerte permanencia en el tiempo, ya que simplifican lo que consideran características específicas de una determinada comunidad nacional. Como todo proceso de construcción social, ese imaginario simbólico, aunque subjetivo, tiene una fuerte base histórica en relación a la consideración del otro como amigo o aliado, enemigo o competidor, y por eso, esas imágenes tienden a socializarse y configurarse según una esencial variable nacional (Álvarez Junco, 1994; Lamo de Espinosa, 2000). Ello permite hablar de una imagen española de Portugal y viceversa, en cuanto están ampliamente socializadas y permanecen de forma consistente en el tiempo (Jover Zamora, 1986).

En el caso de España y Portugal, esas imágenes estereotipadas están todavía más condicionadas, porque los procesos de construcción nacional se han desarrollado dentro de una compleja dinámica de homogeneidad y heterogeneidad. Esto es, la individualización política de ambos Estados ha partido de una previa pertenencia a un tronco común que los identificaba ${ }^{3}$, por lo que la

${ }^{1}$ El presente estudio es fruto del proyecto de investigación del Plan Nacional I+D+I del Ministerio de Economía y Competitividad, "España en la crisis del sistema liberal: una perspectiva externa, 1917-1936", Ref. HAR2012-31460, cuyo investigador principal es el profesor Hipólito de la Torre Gómez.

${ }^{2}$ Debo agradecer al profesor Hipólito de la Torre Gómez la ayuda prestada en la localización y selección de las fuentes documentales utilizadas para la realización de este trabajo.

${ }^{3}$ Mattoso (1998) se interroga sobre la razón por la cual esta unidad de partida desembocó en un proceso de diversidad. Ver Alarção (2007), Sobral (2002) y Mattoso (1985). 
voluntad de construir una comunidad política diferenciada no sólo ha actuado como fuerza centrífuga esencial, sino que también ha sido el factor clave en la construcción de una imagen recíprocamente negativa. En un caso, porque la identidad nacional se ha construido frente al otro, esto es, frente a aquél a quien históricamente se le ha atribuido la condición de enemigo, al acusarle de amenazar permanentemente la independencia nacional del país. En el otro, porque la separación política generó un inveterado espíritu irredentista manifestado de forma polarizada: o bien animando tendencias anexionistas; o bien cayendo en una permanente infravaloración de ese país, que no había aceptado integrarse en lo que el nacionalismo español imaginaba como una comunidad nacional "natural": es decir, el conjunto de la Península Ibérica (Torre Gómez, 2005; Huguet Santos, 2007).

El caso hispano-portugués es, además, significativo por cuanto esa dinámica de heterogeneidad política y homogeneidad cultural se ha configurado desde una significativa asimetría en relación a los criterios de poder relativo existentes entre ambos países. Si se analiza desde una perspectiva puramente geográfica, es evidente que el semicerrado conjunto que conforma la Península Ibérica presenta un claro desequilibrio entre sus dos principales Estados, pues frente al escaso 15,2\% del total que ocupa Portugal se levanta una España que abarca más del $84 \%$ de su superficie total. Asimetría análoga a la que expresan otras variables de poder como, por ejemplo, el peso demográfico, pues si la población de Portugal en 1920 era de 6.032.991, España contaba con 21.388.551. O sea, la población lusa apenas representaba el 28,29\% de la española. Diez años después, la población portuguesa llegaba a 6.825.883, el 28,82\% de la de España, que había alcanzado ya los 23.677.095.

Esta fuerte asimetría, junto a los demás elementos señalados, ha creado una identidad portuguesa de gran recelo frente a ese vecino comparativamente poderoso, y tantas veces, proclive a borrar la frontera intrapeninsular en beneficio de una Península Ibérica políticamente unitaria. Esta presión ha motivado que Portugal se haya volcado históricamente hacia el Atlántico, renunciando a una relación de vecindad activa con España. De hecho, el mar, es decir el Imperio, y España se han configurado como las dos caras complementarias del nacionalismo portugués. Uno asumiendo una dimensión positiva y activa, de cohesión nacional en la realización de una empresa colectiva relevante (Catroga, 1985; Aragão, 1985; Matos, 2008; Godinho, 2004), mientras el anti españolismo ha jugado el papel reactivo de búsqueda de esa cohesión nacional frente al enemigo externo. Hasta el punto de que, de forma a lo mejor algo exagerada, aunque no exenta de alguna razón, hay autores que han afirmado que a partir de 1640, es decir a partir del rechazo a seguir integrado dentro de la monarquía 
hispánica, la historia de Portugal puede ser enteramente interpretada de acuerdo a esa voluntad constante de construir un Estado independiente de España (Rudel, 1968: 139). De forma más precisa se puede afirmar que la histórica política portuguesa de "costas viradas" ha sido la consecuencia de un nacionalismo nacido, alimentado y consolidado a través de una fundamental negación de lo español (Torre Gómez, 1982). Esta dinámica ha derivado, en definitiva, en ese tópico tantas veces repetido de dos países que han vivido de espaldas y que han establecido sus respectivos cauces de intereses internacionales al margen el uno del otro (Telo, Torre Gómez, 2000: 279-287; Horta, Duarte, 1998; Rodríguez Esteban, 1998). Por tanto, a pesar de su posición fronteriza, ninguno de ellos ha sido históricamente zona de interés preferencial para el otro, lo que se ha traducido en unas imágenes recíprocamente negativas, y en una relación de intensidad anormalmente baja a lo largo del tiempo (Jiménez Redondo, 2000; Jiménez Redondo, Loff, 2000).

\section{Iberismo imaginado y realidad política}

La entrada de ambos países en la contemporaneidad acentuó ese paralelismo de sus respectivas trayectorias históricas que ya señalara Joaquim Pedro de Oliveira Martins (1988 [1879]), una de las cumbres de la intelectualidad portuguesa del último cuarto del siglo XIX. Paralelismos que animaron un proceso de convergencia identitaria que resultó infructuoso, orientado a transformar esas imágenes recíprocas de recelo, desconfianza y antagonismo. En efecto, el nacionalismo liberal produjo en los dos Estados un impulso regeneracionista de cambio y aclimatación a la modernidad que les llevó a un profundo cuestionamiento de su propia esencia como nación, permitiendo la aparición de un iberismo de convergencia (Jover Zamora, 1981: LVIII) concebido como una unión o asociación que les permitiera a ambos países transitar hacia la modernidad.

El iberismo es, sin embargo, un concepto complejo, que lleva incluso a hablar de varios iberismos (Almunia, 1994; Cabero, 2002; Cabero, Peralta, 1998; Rina, 2012; Mascarenhas, 1980; Martín Martín, 2009; Rueda, 1998; Matos, 2007; Abreu, 1996; Pereira, 2010). Existió un iberismo claramente político, cuyo objetivo fue la unión política y que adoptó formas, procedimientos y bases ideológicas muy diferentes. Existió, también, un iberismo de base tecnocrática, cuyo objetivo esencial fue construir una unión aduanera, y un mercado lo suficientemente amplio como para permitir que ambas economías pudieran dar el salto a la anhelada modernidad (Velarde Fuentes, 1985; 2002; Jiménez Redondo, 2013a; Pereira, 1996). Finalmente, existió un iberismo cultural que remarcaba la necesidad de aproximación entre la cultura portugue- 
sa y la española, en tanto que conformadoras de una suerte de espacio geocultural ibérico (Durántez Prados, 2014; Pérez Isasi, 2014). Sin embargo, estas diferentes naturalezas del iberismo fueron en muchas ocasiones construcciones más formales que reales, pues, por ejemplo, la práctica totalidad de propuestas españolas sobre la unión aduanera se articularon sobre la base de constituir un instrumento que debía llevar de forma lenta y consensuada a la meta de la unidad peninsular. Y de igual modo, muchos de los estandartes del iberismo cultural acabaron finalmente convencidos de que la identidad cultural expresaba una identidad colectiva y comunitaria que debería concluir plasmándose, tarde o temprano, en una unión política. Otra cosa es que ese objetivo pudiera realizarse por diferentes medios, desde una unión dinástica a la creación de una república federal ibérica; desde una unión aduanera hasta una libre asociación elegida por ambos pueblos.

Por su parte, los iberistas portugueses siempre fueron una elite intelectual que más que aceparlo como un proyecto político positivo, lo consideraron como una poco deseada, aunque inevitable, vía regeneradora que podría conducir a Portugal hacia una modernidad inalcanzable por sí mismo. El iberismo luso siempre tuvo un carácter disruptivo, que estallaba esencialmente en momentos de fuerte sentimiento de decadencia nacional. Siempre fue mayoritariamente impopular, ya que desde hacía mucho tiempo se había desarrollado un sentimiento identitario - protonacional- fuerte, cerrado, particular y defensivo.

En Portugal la conciencia de individualidad nacional fue profunda y socialmente muy extendida, por lo que la idea de España como amenaza fue ampliamente determinante. Sin embargo, en España, el ideal iberista no dejó de ser una imaginación geopolítica propia de un país que seguía soñando con su condición de gran potencia, pero cuya realidad era la de un país crecientemente periférico, dependiente y subordinado.

A partir del último tercio del siglo XIX, el iberismo dejó de basarse en la idea de unión dinástica para pasar a formar parte de las corrientes republicanas federalistas y socialistas, que engarzaron el iberismo con una idea genérica de fraternidad republicana progresista. Conversión esencial, ya que incluyó al iberismo dentro de los imaginarios portugueses y españoles de cambio progresista y de transformación de las propias estructuras estatales. Pero si bien es verdad que esta concepción del iberismo fue significativa en Portugal, aunque también muy controvertida ${ }^{4}$, en el pensamiento republicano y socialista español se impuso ampliamente, al vincular las ideas de progreso, demo-

\footnotetext{
${ }^{4}$ Antero de Quental llegó a insinuar la posibilidad de desistir de la propia nacionalidad, lo que provocó la repulsa de otros intelectuales de cierta filiación iberista como Oliveira Martins o Teófilo Braga.
} 
cracia y reforma del Estado con la desaparición de la monarquía y con el ideal de creación de una República federal ibérica (López-Cordón, 1975).

Ideal que se extendió rápidamente a esos nacionalismos periféricos vasco, gallego y, muy fundamentalmente catalán, que comenzaban a bascular desde sus iniciales posiciones culturales hacia coloraciones más definitivamente políticas. En todo caso, el iberismo luso siempre fue meramente utilitarista, por lo que no puede ser considerado expresión de la existencia de un verdadero nacionalismo ibérico (Rocamora Rocamora, 1994; 1989). Al contrario, su efecto real fue acentuar el carácter exclusivista del nacionalismo unitario portugués (Matos, 2006). Por eso, muy pronto esas veleidades iberizantes cedieron paso a un imaginario simbólico que partía de la idea de que la regeneración del país debía venir no por la pérdida de la nacionalidad sino por la expansión ultramarina. De hecho, el mito imperial acabó imponiéndose frente a las minoritarias alternativas iberistas. La crisis del ultimátum británico de 1890 marcó el último atisbo iberista (Vázquez Cuesta, 1975). Desde entonces, el nacionalismo portugués se reformuló en términos ultramarinos, africanos y, en cualquier caso, dentro ya de un molde exclusivamente lusófono.

Cambio de propuestas, continuidad de respuesta: la revisión de la política portuguesa de Alfonso XIII

A partir de la proclamación de la República en Portugal en 1910, el iberismo pasó a ser sinónimo de peligro español, es decir, pasó a ser visto como una expresión antipatriótica. España volvió a constituirse en la imagen del enemigo que amenazaba la existencia de la nación, y no sólo en términos retóricos, sino reales, como a ojos portugueses demostraban las ideas y, sobre todo, las maniobras políticas de indefinido signo anexionista lideradas por el propio rey Alfonso XIII entre 1911 y 1912 (Torre Gómez, 1983; 1985; 2002; Torre Gómez y Sánchez Cervelló, 2000). De hecho, entre 1910 y 1923 el iberismo constituyó un muro infranqueable para la comunicación política, económica y social entre los dos países ${ }^{5}$, aunque no tanto para unas relaciones culturales e intelectuales que experimentaron un significativo fortalecimiento (Molina, 1990: 14-89).

La intervención en la Primera Guerra Mundial se había saldado para Portugal con la frustrante consideración de ganador sin recompensa. La seguridad de las colonias seguía siendo muy inestable, mientras que el otro objetivo básico de la intervención, equilibrar la relación con España, no sólo no se

${ }^{5}$ La dinámica general de las relaciones peninsulares en Sardica, 2013; Medeiros Ferreira, 1988; Oliveira, 1995; Torre Gómez, 2013; Rivero, 2010; Antunes, 2003. 
había conseguido ${ }^{6}$, sino que el marasmo político en el que se debatía el país, y la mejoría de la consideración internacional de la neutral España, invitada a formar parte del Consejo de la Sociedad de las Naciones, pareció agudizarlo, hasta el extremo de hipertrofiar ese sentimiento de peligro español ${ }^{7}$, o mejor dicho, de frustración nacional. Sin embargo, la política española hacia Portugal estaba en un proceso de cambio, todavía tímido, bien es verdad, pero ya apreciable. Si hasta entonces la política de Alfonso XIII se había caracterizado por un indisimulado deseo anexionista, desde 1919 comenzó a imperar una mayor prudencia e, incluso, un mayor respeto a los asuntos internos del país vecino. El problema es que ese cambio nunca fue enteramente comprendido ni aceptado por los gobernantes $\operatorname{lusos}^{8}$, por lo que a pesar de apreciables gestos de buena vecindad, España nunca dejó de ser considerada el enemigo esencial del país9.

Fue la dictadura de Primo de Rivera la que marcó el momento fundamental de inflexión, ya que el dictador asumió y representó políticamente el cambio sustantivo que el pensamiento nacionalista conservador español estaba experimentando en relación a Portugal ${ }^{10}$, que, a su vez, fue un reflejo del cambio que más tarde representó la obra de António Sardinha en la consideración de España por parte del nacionalismo conservador y reaccionario luso. ${ }^{11}$ Evidentemente, el factor esencial de ese cambio fue la aceptación de las tesis aliancis-

\footnotetext{
${ }^{6}$ João Chagas (1929-1932, Vol. I: 375) escribió textualmente en sus diarios que "ha um aspecto, porem, desta questão que sobre todo me apaixona e que a situação de alta superioridade moral em que a nossa participação na guerra nos colloca ao lado da retrograda e reaccionaria Hespanha".

${ }^{7}$ Son absolutamente claras las intervenciones parlamentarias del presidente de la delegación portuguesa en Versalles (Costa, 1977: 393-400). La frustración de la comparación con España puede verse en un importante artículo de José Almada Negreiros en el que afirma que "España ocupa el lugar que nos pertenece". O Século, 15-V-1919.

${ }^{8}$ Comentando el duro trato que prensa conservadora española dispensaba a la República portuguesa, Melo Barreto los achacaba al hecho ideológico, pero también al "motivo de ser portugueses, lo que muchos españoles todavía no perdonan". Ofício $\mathrm{n}^{\circ}$. 31 . Legação de Portugal em Madrid a Ministro Negócios Estrangeiros. Madrid, 3-II-1920, Arquivo do Ministério dos Negócios Estrangeiros (AMNE), Legação de Portugal em Madrid, (LPM 1917-1931), 3P, A13, M7.

${ }^{9}$ Prueba de ello son los planes de defensa nacional del Estado Mayor del Ejército, cuyo eje central era que la única respuesta posible a una agresión española era el auxilio militar británico (Torre Gómez, 1984: 85-86).

${ }^{10}$ Otras obras clave que dieron impulso a esta concepción geopolítica aliancista fueron las de Bullón y Fernández (1916) y Quintanar (1920).

${ }^{11}$ Un anti iberismo compatible con una profunda alianza entre la monarquía española y su pretendida monarquía lusa que tenía una larga tradición en la publicística política portuguesa. La mejor aproximación en Ferreira (2016).
} 
tas, lo que suponía abandonar los tradicionales postulados anexionistas, en beneficio de una nueva concepción basada en el respeto a la independencia nacional lusa, y la no injerencia en los asuntos internos del país vecino ${ }^{12}$. Pero conviene recordar que esos postulados defendidos por Sardinha y luego por los miembros de Acción Española, fueron exactamente los mismos que el rey Alfonso XIII había puesto en marcha a partir de $1919^{13}$, aunque con una diferencia notable: mientras que el objetivo esencial del integralista luso era la creación de una Península Ibérica políticamente separada, solidaria en sus valores católicos y reaccionarios, que pudiera conformar un "bloque de civilización" iberoamericano partícipe de los mismos principios y valores, la meta de Alfonso XIII fue una amistad que asegurara un papel internacional preponderante a España. Es decir, la idea de alianza preferencial que coadyuvara al engrandecimiento internacional de España. El representante de la Legación portuguesa en Madrid transmitía a su ministro las palabras del Rey en este sentido: "cada una de las naciones aislada, nada vale...juntas...seríamos una fuerza,

${ }^{12}$ La concepción aliancista no alude a la simple asimilación de la obra de Sardinha, como es obvio. Esa concepción, se basaba en el respeto de la identidad nacional de Portugal. Esto es, en la aceptación de que Portugal constituía una unidad nacional diferenciada con la que no cabía imaginar anexiones ni forzadas ni libremente aceptadas. Era un Estado diferente y una nación diferente. Esta concepción aliancista no fue aceptada por todo este universo ideológico, como demuestra esencialmente Juan del Nido y Segalerva, sin duda el autor más influyente de quienes siguieron anclados a las tesis anexionistas. Es decir, al significado literal de tal término: Unir o incorporar algo, especialmente un país o una parte de su territorio, a otro. Es tan absolutamente evidente este sentido anexionista que Nido (1914) se concentra en el estudio del concepto del que participa, es decir, de unión ibérica, independientemente del camino que el político conservador dibujara acerca de la mejor forma de alcanzar ese objetivo que, en su opinión era por medio de una fórmula de doble monarquía o monarquía federal encabezada, como no, "sorprendentemente" por el rey español, Alfonso XIII. Ver también Nido (1915). Interesantes también Gay y Forner, 1915; Pérez de Andreu, 1924). Vergara (1925) abogaba por una federación ibérica basada en que españoles y portugueses constituían una única raza y, por lo tanto, una sola nación.

${ }^{13}$ Como recogen los representantes diplomáticos lusos, el deseo del Rey de un estrechamiento efectivo, concreto y real de relaciones es una constante desde 1919, igual que su insistencia en la total y absoluta aceptación de la separación política de ambas naciones. Por ejemplo, Telegrama $\mathrm{n}^{\circ}$ 47. Ministro Negócios Estrangeiros a Embaixador de Portugal em Londres, Lisboa, 22-VII-1919. AMNE. Legação de Portugal em Londres, (LPL) Caixa 123. También, Telegrama ${ }^{\circ}$. 272. Legação de Portugal em Madrid a Ministro Negócios Estrangeiros. Madrid, 15-6-1926. AMNE, Telegramas LPE a MNE, 1926. El problema era que ese inveterado nacionalismo anti español acabó consolidando la idea de que si bien el Rey aceptaba la amistad con Portugal, no ocurría lo mismo con muchos miembros de sus gobiernos, "que no participan de los propósitos manifestados por el jefe del Estado". Ministro Negócios Estrangeiros a ministro de Portugal em Madrid. Lisboa, 16-10-1922. AMNE. LPM. 3P, A13, M7. En este mismo sentido Telegrama no 30 Ministro Negócios Estrangeiros a Legação de Portugal em Madrid. Lisboa, 7-IX-1920. AMNE. Telegramas de MNE a LPM, 1920. 
un valor enorme". Además, esta alianza preferencial tenía como objetivo apartar a Portugal de su tradicional aliado británico, que según Alfonso XIII, como señalaba Melo Barreto, representaba "un interés ajeno en que no nos entendamos"14.

La más que modesta repuesta portuguesa a esta evolución indica hasta qué punto el peligro español era un instrumento de política interna portuguesa, asociado ahora al peligro reaccionario de un monarquismo tenazmente conspirativo. Pero era una utilización espuria de España como enemigo, ya que el gobierno español se mantuvo esencialmente al margen de todas las iniciativas de desestabilización de la República portuguesa, especialmente de la llamada monarquía del Norte, un movimiento insurreccional de casi un mes de duración (Comesaña Paz, 2013: 438-700; Santos, 2011). Otra cosa es que los conspiradores encontraran la complicidad de algunas autoridades locales cercanas a la frontera y que, sobre todo, tuvieran el apoyo moral y material de personas individuales como Vázquez de Mella, unidas por una auténtica solidaridad ideológica y un indudable espíritu de comunión conspirativa contra un sistema democrático que denostaban por igual ${ }^{15}$. No compartían, por tanto, una mera identidad monárquica, sino una esencial identidad ideológica basada en el rechazo cada vez más frontal a la práctica de un parlamentarismo percibido como desordenado y caótico, de unos partidos políticos considerados como facciones ajenas al interés general y de una cultura, en su opinión, cada vez más materialista y alejada de la esencia de los valores católicos entendidos en un sentido integral.

\section{Primo de Rivera y la ¿nueva? percepción de España}

La inestabilidad estructural de la República portuguesa siguió alimentando ese peligro español que, en realidad, era el reflejo de un profundo sentimiento de inseguridad frente a la creciente confluencia de los adversarios del régimen

${ }^{14}$ Ofício $\mathrm{n}^{\circ}$ 103, Legação de Portugal em Madrid a Ministro Negócios Estrangeiros. Madrid, 31-V-1922. AMNE. LPM, 3P, A13, M7. La idea de Gran Bretaña como ese gran enemigo de España que le ha impedido realizar sus históricas pretensiones geopolíticas (Gibraltar, federación con Portugal, expansión espiritual hacia América) es esencial en todo el pensamiento conservador y reaccionario español, especialmente, por influencia de Juan Vázquez de Mella. Aunque en el caso portugués, su discurso federalista será muy pronto sustituido por el argumento aliancista (Vázquez de Mella, 1915). El desarrollo de su idea de federación ibérica en Vázquez de Mella (1915: 47 y ss).

${ }^{15}$ Esta identidad ideológica que conllevaba la agria crítica al republicanismo democrático aparece claramente reflejada en una de las, por otra parte y a pesar de ese indisimulado sesgo ideológico señalado, grandes obras de referencia del lusitanismo español (Pabón, 1945). 
instalado en 1910. Miedo acrecentado por la actitud de unas fuerzas armadas cada vez más persuadidas de que solamente ellas eran capaces de acabar con el caos y el desorden que para una mayoría de sus integrantes representaba el gobierno republicano. Por eso acogieron con indudable temor el golpe militar protagonizado por el general Primo de Rivera en España, al considerar el efecto de emulación que podía desencadenar en su propio país. De ahí que la recepción de la recién instalada dictadura fuera realmente negativa y dura por parte de los medios afines al republicanismo gobernante, llegando incluso, como ponía de manifiesto el jefe de la legación diplomática lusa en Madrid, a que "insultan a las personas que encarnan a ese régimen, sin excepción del Rey"16.

Sin embargo, la reacción del nuevo gobierno español fue de absoluta indiferencia frente a esos ataques mediáticos. Desde el inicio de su gobierno, Primo de Rivera asumió el aliancismo peninsular como un vector absolutamente esencial y determinante de su política exterior ${ }^{17}$, a la que no estaba dispuesto a renunciar, independientemente de la receptividad que esta política pudiera tener en Lisboa. Y era así porque esa idea de alianza era el soporte de un modelo de política exterior de corte regeneracionista articulado sobre una esencial base iberoamericana, entendida dentro de la conceptualización de "la Raza"18. El concepto de aliancismo no surge de la obra Alianza Peninsular de Sardinha. Precisamente, el integralista luso pudo llegar a sistematizar esta idea porque previamente se había iniciado un proceso de aproximación empática entre el pensamiento conservador, entendido en sentido amplio, español y portugués. Especialmente, en el asentamiento de una cosmovisión basada en un catolicismo integrador que debía unir "naturalmente" a las naciones católicas iberoamericanas. Esto es, sobre la imaginación geocultural de conformación de un bloque supranacional de tintes espirituales basado en la identidad católica, políticamente teñido de una clara tendencia autoritaria, y culturalmente muy conservador y aún reaccionario ${ }^{19}$. Lo que hace Sardinha en su obra es aproximarse ideológicamente a esa imaginación geopolítica hispánica que ya

${ }^{16}$ Ofício no 229. Legação de Portugal em Madrid a Ministro Negócios Estrangeiros. Madrid, 24-IX-1924. AMNE, LPM. 3P, A13, M7.

${ }^{17}$ Según transmitía el ministro portugués, el programa del gobierno de Primo de Rivera y los deseos del propio rey era que las relaciones alcanzaran, "en provecho de las dos naciones hermanas, una orientación cuyo significado exceda el existente". Ofício $\mathrm{n}^{\circ} 178$. Legação de Portugal em Madrid a Ministro Negócios Estrangeiros. Madrid, 21-9-1923. AMNE, LPM. 3P, A13, M7.

${ }^{18}$ Un análisis atractivo, sugerente y controvertido del concepto en Marcilhacy (2010a). Del mismo autor, Marcilhacy (2010b). Una visión de conjunto en Sepúlveda (2005).

${ }^{19}$ Esta idea de bloques de poder fue una constante del pensamiento internacional y geopolítico de las derechas europeas de los años veinte y treinta. Un ejemplo portugués es el desarrollado por el periodista Correia da Costa en Diário de Notícias, 22-2-1926. 
desde la Restauración había sido aceptada por esa intelectualidad conservadora y reaccionaria española, y que con el transcurrir del tiempo llegó, incluso, a verse salpicada por un incipiente pensamiento fascista, más volcado hacia una idea de reconstitución política de la Península.

Como se ha señalado, las bases teóricas de esta nueva concepción aliancista quedaron definitivamente fijadas con António Sardinha (1930 [1924]), que actualizaba toda una forma de ver y relacionarse con España, y con lo que denominaba el mundo hispánico del que, en su opinión, Portugal formaba parte indisoluble. Esta visión no era original en modo alguno (Jiménez Redondo, 2013b; Ferrerira, 2016; Chacon, 2005: 179 y ss; Gomes, 2015), pero resultó esencial por ubicarse dentro del espectro ideológico del nacionalismo conservador y reaccionario luso, que siempre se había definido en términos antiespañoles. El propio Sardinha (1930 [1924]: 49) lo señalaba al decir que: "la tara más grave del patriotismo portugués que, disminuyendo y ocultando todo lo que hay de universal en nuestro genio, parece instituir como condición fundamental de nuestra independencia un odio profundo, un odio ciego, un odio irracional a España".

No conviene olvidar que si bien la recepción de Sardinha en la España conservadora y reaccionaria fue casi completamente entusiasta ${ }^{20}$, no ocurrió lo mismo en ese mismo universo ideológico luso, donde las visiones acerca de España comenzaron a partirse. Si por un lado algunos integralistas como José Pequito Rebelo se adscribieron a esta idea aliancista admitiendo que una España y un Portugal "sanos" en términos políticos, es decir, bajo los postulados autoritarios y reaccionarios típicos del integralismo, deberían formar un sólido bloque de acción; otros como Alfredo Pimenta (1935 [1934]) continuaron absolutamente anclados en la idea del anti españolismo como componente básico, esencial y definidor de la identidad nacional portuguesa.

En todo caso, es evidente que el discurso monolítico del nacionalismo conservador y reaccionario portugués se estaba rompiendo, tanto, que estas derechas portuguesas, tradicionalmente nacionalistas en su sentido clásico de antiespañolas, tuvieron que matizar su discurso con el fin de poder conciliar esos dos conceptos hasta entonces antitéticos: nacionalismo portugués y alianza

\footnotetext{
${ }^{20}$ Ya que todavía perduraron las concepciones anexionistas que fueron retomadas por Falange dentro de esa fórmula difusa de comunidad de destino en lo universal. Estas posiciones fueron secundarias en los años veinte, pero no en los cuarenta en el contexto de la Segunda Guerra Mundial, con personajes tan influyentes como Camilo Barcia Trelles (1939) o José María Cordero Torres (1944). Incluso la célebre obra de José María de Areilza y Fernando María Castiella, Reivindicaciones de España (1941), resultaba claramente ambigua en relación a Portugal.
} 
peninsular. O dicho de otra forma, el problema al que se enfrentaron fue el paso simbólico y efectivo de España, y de lo que ella significaba en su tradicional concepción de enemigo, a la idea de una España aliada de Portugal. El golpe de Estado militar en Portugal en 1926 y, sobre todo, la llegada de Salazar al poder acabaron por asentar esta evolución, aunque el verdadero y definitivo motor de transformación de la imagen de España fue la reacción de la dictadura salazarista y de sus intelectuales y propagandistas a la implantación y desarrollo de la República en España a partir de 1931.

¿Cuál fue, en definitiva, a ojos portugueses, la contribución del general Primo de Rivera a esta evolución estructural de las relaciones luso-españolas? Esencial, pues una cosa eran los discursos geopolíticos construidos desde una perspectiva puramente formal o meramente intelectual, y otra muy diferente la articulación real y efectiva de una geopolítica práctica, es decir, si se quiere expresar de otra forma, un verdadero modelo de política exterior basado en una definición implícita y tácita de los intereses nacionales de España y la articulación de los medios para alcanzar esos objetivos previamente definidos. Evidentemente, el resultado final fue limitado, pero, en todo caso, constituyó un ejemplo práctico de articulación y puesta en práctica de un incipiente modelo ideológico de política exterior, que fue evidentemente muy bien recibido en Lisboa, claro está, a partir de 1926.

Es dentro de esta nueva imaginación geopolítica de regeneración de la imagen y la presencia internacional de España desde la que se entiende, en toda su extensión, la política portuguesa de Primo de Rivera. ${ }^{21} \mathrm{Y}$ es desde estos postulados desde los que se explica la multiplicación de gestos amistosos que Madrid dirige a Lisboa. El más significativo de ellos fue, sin duda, el ofrecimiento hecho por el gobierno de España de proporcionar al país vecino una asistencia financiera que paliara en lo posible la penosa situación que atravesaban desde el fin de la guerra mundial las finanzas públicas lusas ${ }^{22}$. Demostración importante de simpatía, pero desoída por Lisboa, ya que a sus ojos recordaba en demasía a esos viejos gestos de supuesta amistad que encubrían, desde su perspectiva, deseos hegemónicos. Por muy frecuentes e incluso sinceros que pudieran ser y parecer las propuestas aliancistas españolas, en el Portugal

${ }^{21}$ Algo de lo que eran perfectamente conscientes en Portugal. Ofício $n^{\circ} 103$. Legação de Portugal em Madrid a Ministro Negócios Estrangeiros. Madrid, 31-5-1922. AMNE, LPM. 3P, A13, M7.

${ }^{22}$ Ofício no 88. Legação de Portugal em Madrid a Ministro Negócios Estrangeiros. Madrid, 12-V-1924, AMNE, LPM, 3P, A4, M2. Ofrecimiento reiterado por el propio Alfonso XIII cuatro años después. Ofício $\mathrm{n}^{\circ} 11$. Embaixador de Portugal em Madrid a Ministro Negócios Estrangeiros. Madrid, 9-I-1928. AMNE. LPM. Caixa 151. 
republicano continuaba demasiado vivo el recuerdo de ese tradicional peligro español, hipertrofiado en los últimos años. A pesar de ello, la insistencia del dictador en sus propuestas de amistad fue poco a poco creando un efecto de lluvia fina que comenzó a calar en el gobierno del país vecino, ${ }^{23}$ aunque todavía distaba mucho de poder considerar que ese nacionalismo portugués, y la mentalidad colectiva anti española que llevaba tanto tiempo alimentando, estaba superada.

\section{La primera convergencia autoritaria}

El 28 de mayo de 1926 un golpe de Estado militar acabó con el régimen establecido en 1910, abriendo un periodo de dictadura militar que acabó alumbrando un nuevo régimen autoritario bajo el liderazgo de Antonio de Oliveira Salazar. El proceso político portugués se encaminó, en definitiva, hacia una solución autoritaria de larga duración que parecía similar a la que España había ensayado desde 1923. En consecuencia, la empatía ideológica contribuyó decisivamente a un efectivo cambio en la percepción de ese peligro español identificado como peligro reaccionario, ya que la coincidencia ideológica identificaba un mismo enemigo: el enemigo ideológico a las dictaduras, visto por ambas como el peligro revolucionario y bolchevique ${ }^{24}$.

En otras palabras, la identidad ideológica generó un potente factor de convergencia entre los dos gobiernos que pronto se percibieron como apoyo recíproco en su común propósito de acabar con los sectores de oposición que todavía ponían en cuestión su permanencia. De ahí la indisimulada alegría con la que Madrid recibió al nuevo gobierno militar de Lisboa, y su convencimiento de que se abría una posibilidad única para el estrechamiento efectivo de las relaciones entre los dos países. Y para demostrarlo, decidió insistir en una propuesta que permanecía olvidada: elevar el rango de la representación diplo-

${ }^{23}$ Telegrama ${ }^{\circ}$. 157. Ministro Negócios Estrangeiros a Embaixador de Portugal em Londres. Lisboa, 24-IV-1926. AMNE. LPL, caja 123.

${ }^{24}$ Son frecuentes las expresiones de temor ante este nuevo enemigo común. Por ejemplo, en 1925 Melo Barreto recoge unas palabras de Alfonso XIII sobre el posible reconocimiento de la Unión Soviética en las que decía que España y Portugal no deberían hacerlo, dada su "impresionabilidad, -hermanos de raza- pueblos sensibles, de emoción, pueblos soñadores". Lo contrario que Inglaterra, que podía proceder a ese reconocimiento sin peligro ya que era una nación "ponderada, reflexiva, con sentimientos admirables de la proporción y las realidades... desengañémonos, los ingleses no poseen, es cierto, nuestras cualidades, pero tienen mucho más juicio que nosotros". Tampoco veía peligro en Francia, por su respeto al principio de autoridad y el predominio de las clases medias, facultades que le daban "condiciones especiales de defensa contra los asaltos extremistas". Ofício $\mathrm{n}^{\circ} 103$. Legação de Portugal em Madrid a Ministro Negócios Estrangeiros. Madrid, 19-VI-1925. AMNE. LPM, 3P, A4, M3b. 
mática de España al rango de embajada. Gesto que fue inmediatamente aceptado, ya que suponía un evidente respaldo internacional al gobierno militar surgido del golpe de Estado ${ }^{25}$. El muy influyente Diário de Notícias, aclaraba el significado de ese acto y la nueva imagen que se quería transmitir de España y Portugal como "países, consanguíneos, hermanos, combatiendo juntos, descubriendo el mundo juntos"26.

Podría pensarse que esta formulación aliancista fue un mero recurso retórico o puramente ideológico de los dos regímenes militares. Pero no fue así. El cambio del discurso generó una verdadera transformación de las percepciones recíprocas, especialmente de ese inveterado recelo antiespañol propio del nacionalismo luso, lo que a su vez, se transformó en posibilidades reales de dar contenido efectivo a esa relación. En apenas tres años, se cerraron importantes acuerdos que llevaban atascados muchos años. Por ejemplo, el Acuerdo de Límites de 29 de junio de 1926, el acuerdo para el aprovechamiento del tramo internacional del Duero de 1927, el tratado de conciliación y arbitraje de 1928, la celebración de una conferencia económica conjunta en 1928, etc. Acuerdos, y también demostración de estima personal y política, como la manifestada por Alfonso XIII hacia el entonces presidente de la República portuguesa general Oscar Carmona ${ }^{27}$ en un ejercicio de diplomacia personal, pero que tuvo también una dimensión pública que, con toda la carga simbólica que representaba, tuvo su principal manifestación en la visita oficial del presidente Carmona a España en octubre de 1929. Previamente había tenido lugar un doble encuentro informal entre el general Primo de Rivera y el primer ministro luso Ivens Ferraz, retrasado en numerosas ocasiones, pues todavía persistía un cierto temor a que este visible estrechamiento de relaciones pudiera causar ciertos recelos en la opinión pública portuguesa (Oliveira, 1985: 218; Fernández Clemente, 1997: 46-48).

Pero lo cierto es que la bien preparada visita de Carmona fue una exaltación propagandística de esta nueva vertiente aliancista, al ser presentada como "la coronación lógica de la política de aproximación e íntima amistad" 28 , lo que

${ }^{25}$ Telegrama $n^{\circ}$ 267. Legação de Portugal em Madrid a Ministro Negócios Estrangeiros. Madrid, 9-6-1926. Telegrama $\mathrm{n}^{\circ}$ 103. Ministro Negócios Estrangeiros a Legação Portugal em Madrid. Lisboa, 10-6-1926. La respuesta de Madrid en Telegrama n 268. Legação de Portugal em Madrid a Ministro Negócios Estrangeiros. Madrid, 12-6-1926. Telegrama n 272. Legação de Portugal em Madrid a Ministro Negócios Estrangeiros. Madrid, 15-6-1926. AMNE, Telegramas LPE a MNE, 1926.

${ }^{26}$ Diário de Notícias, 22-2-1926.

${ }^{27}$ Ofício ${ }^{\circ} 10$. Embaixador de Portugal em Madrid a Ministro Negócios Estrangeiros, Madrid, 5-I-1929. AMNE, LPM, 1929, 3P, A4, M7.

${ }^{28}$ Diário de Notícias, 16-10-1929. 
no quería decir que Portugal hubiera trastocado su tradicional eje de sustentación internacional, pues como señalaba el diario O Século, el viaje de Carmona a Madrid no significaba en modo alguno encaminar la política externa portuguesa por "caminos diferentes" a los tradicionales. Es decir, a la histórica Alianza Británica ${ }^{29}$.

La escenificación simbólica de esta nueva entente peninsular debía concluir con la visita oficial del rey Alfonso XIII a Portugal, prevista para finales de ese año. Sin embargo, la dictadura española entró en una rápida fase de crisis y agotamiento, resuelta con la dimisión del general Primo de Rivera en enero de 1930. La primacía, una vez más, del conflicto interno, se impuso a cualquier dimensión de política exterior, por lo que el gobierno del general Berenguer agotó esta fase de entendimiento peninsular que a pesar de los grandes avances conseguidos, no había sido capaz de remover todo ese fondo estructural antiespañol del nacionalismo luso, y la extensión y arraigo popular de esas tradicionales imágenes negativas de España en el país vecino.

Y tampoco había hecho que el nuevo gobierno luso se planteara cualquier modificación de su alianza con Gran Bretaña, que hay que recordarlo, tenía una raíz defensiva y preventiva evidente contra España. Así lo había manifestado el ministro Vasco Borges antes del golpe de Estado del 28 de mayo de 1926, ${ }^{30}$ y así lo volvió a remarcar el ministro de Exteriores de la Dictadura Militar tras la visita del presidente de la República Oscar Fragoso Carmona a España en 1929. Según el ministro, se había tratado de un "viaje de cortesía, que demostraba las buenas relaciones en que viven los dos países, sin cualquier finalidad política... Tan conocida y tan firme es la orientación política externa el Gobierno de la República, siempre dentro del marco de nuestras tradicionales relaciones con Inglaterra" 31 .

\section{El fin de la Dictadura y la nostalgia del autoritarismo primorriverista}

Salazar (1945: 27) siempre partió del imperativo categórico de la dualidad política ibérica, considerando que la mejor forma de asegurar ese objetivo era a través de la buena vecindad peninsular, por lo que siempre asumió que la amistad con España constituía uno de los factores básicos del interés nacional portugués. Pero esa buena vecindad siempre tuvo para el dictador luso un contenido profundamente ideológico. Es decir, partía de la base de que no

${ }^{29}$ O Século, 17-10-1929.

${ }^{30}$ Telegrama no 57 . Ministro Negócios Estrangeiros a Embaixador de Portugal em Londres. Lisboa, 24-IV-1926. AMNE. LPL. Caixa 123.

${ }^{31}$ Telegrama Ministro Negócios Estrangeiros a Embaixador de Portugal em Londres. Lisboa, 1-VI-1929. AMNE. LPL, Caixa, 123. 
podía ser incondicional, sino dependiente del régimen político que existiera al otro lado de la Raya, y desde muy pronto percibió al nuevo régimen español como claramente incompatible con su proyecto de construcción del Estado Novo, al ser catalogado como radical, revolucionario y federalista. Estos tres factores alimentaron esa nueva representación del viejo peligro español concebido otra vez como "peligro ideológico" español, aunque esta vez esa dimensión ideológica había pasado del "peligro reaccionario" típico del periodo 19101926 al "peligro revolucionario"32. De ahí que la propaganda del incipiente salazarismo se lanzara a una permanente descalificación de la República y de los republicanos españoles, descritos por la propaganda salazarista como criptocomunistas al servicio de la destrucción del Estado Novo, y como unos inveterados iberistas cuyo objetivo de fondo era acabar con la propia existencia de Portugal (Pena Rodríguez, 1998).

Pero esta dimensión ideológica obligó al nacionalismo conservador y reaccionario luso, aglutinado en torno al nuevo régimen salazarista, a una reflexión importante que venía a demostrar la importancia real y el calado del discurso aliancista popularizado por António Sardinha, ya que en gran medida fue el discurso oficial de una parte mayoritaria de la intelectualidad estadonovista. Frente a ese nacionalismo que seguía anclado en un antiespañolismo sin matices, comenzó a imponerse una imagen claramente ideológica de España, según la cual ésta no representaba ya un peligro, ni era ese enemigo absoluto de Portugal. El peligro era la tendencia revolucionaria de la España republicana ${ }^{33}$.

32 En los últimos dos años de su reinado, Alfonso XIII mostró ante el embajador portugués su aprensión a esa tensión revolucionaria. En 1929 advertía al embajador sobre una reunión celebrada en París por emigrados políticos "adversarios de las dictaduras de España, Portugal e Italia con predominio de elementos masones" convocada para llevar a cabo movimientos revolucionarios que afectarían a esos tres países. "El Rey, añadió, estar informado de que Portugal sería de los tres países de régimen dictatorial, el escogido para la primera tentativa de alteración del orden público". Ofício n ${ }^{\circ} 34$. Embaixador em Madrid a Ministro Negócios Estrangeiros. Madrid, 24-I-1929. AMNE. LPM. 3P, A4, M7c. A pocas semanas de la proclamación de la República en España, el Rey le decía al embajador que los intentos insurreccionales respondían a intentonas de los comunistas que "sacrificarían si triunfasen a los elementos republicanos, sus colaboradores indispensables". Según relata el embajador, el Rey no pensaba en esos momentos que pudiera proclamarse una República en España sin el peligro inmediato del comunismo, algo que no sucedió en Portugal porque la implantación de la República en 1910 se había producido en un momento en el que "el bolchevismo no se había implantado todavía como forma de gobierno". Ofício n ${ }^{\circ} 35$. Embaixador em Madrid a Ministro Negócios Estrangeiros. Madrid, 9-I-1931. AMNE. LPM. 3P, A4, M12.

${ }^{33}$ El entonces ministro de Portugal en Berna Vasco Quevedo, decía textualmente que "La República no fue proclamada por una elite intelectual de pensadores empapados de la ideología de una democracia burguesa y libro. No. La República española se hizo fruto de la confluencia de los socialistas, comunistas, sindicalistas y anarquistas". Ofício n ${ }^{\circ} \mathrm{A}-15$. Legação de Portugal em Berna a Ministro Negócios Estrangeiros. Berna, 5-IV-1932. AMNE. 3P, A13, M9. 
España era un peligro porque el comunismo había anidado en la República y amenazaba con extenderse a Portugal y acabar con el Estado Novo. Lo verdaderamente peligroso de España era el carácter federalista e iberizante de las izquierdas españolas, pues como afirmaba el embajador de Portugal en Londres, eran tendencias que "aunque no siendo realmente apoyadas de forma oficial por el nuevo Gobierno, corresponden al sentimiento de la inmensa mayoría de los españoles" 34 . Sin embargo, esta percepción conllevaba la convicción opuesta. Es decir, España sería amiga y aliada si virase política e ideológicamente hacia postulados asimilables con el Estado Novo. El peligro español podría dejar paso a una nueva versión de la entente aliancista vivida durante la Dictadura de Primo de Rivera si existiera, como entonces la hubo, una efectiva convergencia política e ideológica.

Cierto es que en términos puramente defensivos y geopolíticos, la política autonomista de los gobiernos republicanos podría disminuir notablemente la presión centrípeta que España ejercía en el conjunto peninsular, pero para los representantes diplomáticos lusos era una alternativa escasamente satisfactoria en comparación con los riesgos de contagio que podría provocar el federalismo republicano. La respuesta a este dilema ofrecida por el Embajador en Madrid es absolutamente expresiva de esta visión. Al comentar una conferencia pronunciada por José María Pemán de exaltación de la monarquía como única fuerza real de unificación que existía en España, decía el embajador que "constituye un error cualquier aliento de la opinión portuguesa, aunque tenue, a la propaganda de los republicanos españoles, federales por su tradición y por su programa. Un error desde el punto de vista republicano, y un crimen desde el punto de vista nacional. Lo que conviene, por lo demás, a la República Portuguesa es que perdure la Monarquía Española unitaria"35. Esa monarquía unitaria que según Melo Barreto "tendrá todos los defectos menos el de querer mal a nuestro país y el de constituir una amenaza para la independencia de Portugal" 36 .

Pero, ¿la República constituía realmente un peligro para Portugal o lo era solamente para Salazar y su régimen? Ya en febrero de 1931, el embajador por-

${ }^{34}$ Embaixador de Portugal em Londres a Ministro Negócios Estrangeiros. Londres, 6-VI1931. AMNE. LPL. Caixa 123 (transcrito en Torre Gómez, 1988: 131-132).

${ }^{35}$ Ofício $\mathrm{n}^{\circ}$ A-149. Embaixador de Portugal em Madrid a ministro Negócios Extrangeiros. Madrid, 7-II-1931. AMNE. LPM 3P, A13, M9.

${ }^{36}$ Ofício $\mathrm{n}^{\circ} 235$. Embaixador de Portugal em Madrid a Ministro Negócios Estrangeiros. Madrid, 17-III-1930. AMNE. LPM, 3P, A4, M11. Igual afirmación en Ofício n ${ }^{\circ} 496$. Embaixador de Portugal em Madrid a Ministro Negócios Estrangeiros. Madrid, 14-IX-1929. AMNE. LPM. 3P, A4, M7c. Ofício no 590. Embaixador de Portugal em Madrid a Ministro Negócios Estrangeiros. Madrid, 25-VII-1930. AMNE. LPM. 3P, A4, M1lb. 
tugués en Madrid advertía sobre el "peligro de la estructura federal del Estado y los elogios calurosos obra heroica de Rusia de los Soviets - dos de los focos dominantes de la propaganda republicana española- cualquiera de ellos de acentuado peligro, desde el punto de vista que pueda tener, aunque sea simplemente moral, sobre la vida política portuguesa"37.

El iberismo republicano era bastante difuso puesto que dentro del pensamiento internacional del republicanismo español Portugal aparecía como un elemento más de una hipotética federación de pueblos hispánicos en un marco general de respeto a la soberanía de todos ellos. Pero no todo era una nebulosa retórica en torno a un republicanismo federalista ibérico de ensoñación. Los gobiernos republicano-socialistas apoyaron de forma explícita a los exiliados antisalazaristas que residían en España, tanto a anarquistas y comunistas como a importantes personalidades del extinto régimen democrático, proporcionándoles no sólo ayuda y cobijo, sino apoyo en forma de subsidios económicos para la adquisición de armas, instrumento indispensable para la revolución.

Otra cosa es que ese apoyo fuera esencial para el triunfo de las intentonas antisalazaristas, o que la capacidad de contagio revolucionario pudiera alcanzar cotas que realmente hicieran peligrar una situación política ya bastante asentada a la altura de 1936. Pero es evidente que desde la perspectiva del salazarismo la España republicana volvía a ser ese enemigo tradicional que, sin embargo, durante la dictadura de Primo de Rivera parecía haberse diluido. Por eso no es extraño que apareciera una evidente nostalgia de ese momento y del propio general Primo de Rivera. En palabras del embajador Melo Barreto, un "ilustre militar y hombre de Estado, gran y sincero amigo de Portugal" ${ }^{18}$.

Conviene recapitular recogiendo unas palabras del premio Nobel de Literatura José Saramago. Decía el escritor que él: "como cualquier otro portugués antiguo y moderno, fui instruido en la firme convicción de que mi enemigo natural es, y siempre habría de serlo, España. No atribuíamos demasiada importancia al hecho de que nos hubiesen invadido y saqueado los franceses, o que los ingleses, nuestros aliados, nos hubiesen explotado, humillado o gobernado: esos no eran más que episodios históricos corrientes que teníamos que aceptar de acuerdo con las reglas de un relativismo práctico, ese que precisamente nos enseña a relativizar, esto es, a tener paciencia. Absoluto, lo que se dice absoluto, desde nuestro punto de vista de portugueses, sólo el rencor al castellano, sentimiento llamado patriótico en que fuimos infatigables en el trans-

${ }^{37}$ Ofício ${ }^{\circ}$ 193. Embaixador de Portugal em Madrid a Ministro Negócios Estrangeiros. Madrid, 13-II-1931. AMNE. LPM. 3P, A4, M12a.

${ }^{38}$ Ofício ${ }^{\circ}$ 303. Embaixador de Portugal em Madrid a Ministro Negócios Estrangeiros. Madrid, 5-4-1930. AMNE, LPM, 3P, A4, M11. 
curso de los siglos, lo que, quien sabe, nos habrá ayudado por el rechazo y la contradicción, a formar, robustecer y consolidar nuestra propia identidad nacional" (Saramago, 1990: 5-6).

Lo que Saramago reflejaba, con una ironía no exenta de sentido reproche, es esa dimensión socializada del iberismo como núcleo articulador del nacionalismo luso, lo que permite comprender su utilización recurrente por las elites políticas lusas como un mito de movilización y cohesión nacional -el llamado peligro español-, esto es, como un mito negativo articulador de la propia identidad nacional en sus aspectos de confrontación con un enemigo, en ocasiones supuesto, en otras real, que amenazaba esa identidad nacional. Esto ha configurado una imagen tradicional de España como enemigo que ha perdurado prácticamente hasta la actualidad.

Primo de Rivera fue un estímulo de cambio, sustancial es cierto, pero en todo caso, un estímulo que acabó abruptamente en 1931, o incluso un año antes, cuando presentó su dimisión al Rey. La asimetría política y la naturaleza político-ideológica del salazarismo en oposición a la Segunda república española explican esa interrupción. Más tarde, la guerra civil y el triunfo de los militares liderados por Franco en España volvieron a unificar ideológicamente la Península y a consolidar la idea de convergencia autoritaria, lo que acabó casi definitivamente con la idea de España como sinónimo de peligro español.

Pero la otra España y el otro Portugal, los de los exilios y las oposiciones a las dictaduras, también contribuyeron a generar una imagen propia del otro peninsular. En esos círculos, los ideales iberistas continuaron siendo relevantes, aunque como ya sucediera en muchas otras ocasiones a lo largo de la historia, esa idea iberista era más una apuesta por una nueva España y un nuevo Portugal, democráticos y desarrollados, que un ideal anexionista puro. Y en España ese iberismo era también como antaño, una forma de pensar una nueva articulación territorial que permitiera satisfacer las demandas de autogobierno de esos nacionalismos periféricos que creían que el final del franquismo debía suponer, necesariamente, un reconocimiento de la personalidad específica y diferenciada de las distintas naciones que, desde estas perspectivas, conformaban España.

\section{Conclusiones $^{39}$}

La intervención portuguesa en la Primera Guerra Mundial no había alterado la fundamental asimetría de poder relativo existente entre España y Portugal.

${ }^{39}$ Las conclusiones globales coinciden necesariamente con las aportadas por varios autores con anterioridad. Principalmente con las ya señaladas por Hipólito de la Torre, que 
En estas circunstancias, el gobierno luso fue consciente de que ese buscado reequilibrio solamente podía venir por acentuar la función anti ibérica y de salvaguarda del imperio colonial que históricamente había desempeñado la Alianza Británica. Esta asimetría, y el profundo marasmo político en el que vivía el país, hipertrofió el tradicional fantasma del peligro español en un momento en el que la política española hacia Portugal había iniciado un significativo proceso de cambio, basado en un principio de respeto a la soberanía del país y de no injerencia en sus asuntos internos. El problema es que ese cambio no fue percibido como tal desde el otro lado de la Raya.

Las propuestas españolas de fraternidad ibérica tenían como objetivo alcanzar una alianza preferencial que contribuyera al engrandecimiento internacional de España. También, y es una línea que se repetirá después, tenían como fin desplazar la influencia británica de la Península y, en definitiva, generar un conjunto de solidaridades materiales que permitieran ir tejiendo un manto de interdependencia que concluyera en una solidaridad política que autorizara presentar ante el mundo un espacio común ibérico íntimamente integrado. Pero estos ofrecimientos de amistad fueron vistos como una invitación envenenada que encubría una subordinación a los designios de Madrid, por lo que la única respuesta que creyeron posible fue soldar aún más su dependencia respecto de Gran Bretaña. En definitiva, por muchos gestos de buena vecindad que se sucedieran, España no dejó de ser considerada el enemigo esencial del país, y aquél sobre el que debía concentrarse el esfuerzo defensivo nacional.

La dictadura de Primo de Rivera ayudó a cambiar la percepción portuguesa, aunque en un primer momento, la militarización de la política española

fue el primero en observar, comprender y valorar de forma tan sutil como medida, el concepto del iberismo no como un mero ejercicio intelectual, sino que supo extraer su significado profundo en términos ideológicos y políticos. Otros autores como Chato González o Sánchez Cervelló (1998) llegan a conclusiones muy parecidas. Una cosa es analizar el iberismo como repertorio de obras y describir las propuestas incluidas en ellas, y otra diferente analizar el iberismo en la dinámica de las relaciones peninsulares y, en especial, su condición de condicionante estructural de las mismas y su consideración en cada uno de los dos países. Sobre todo, en Portugal pues como refleja toda la documentación oficial portuguesa del siglo XIX y también del XX, hasta muy avanzado el siglo es sistemáticamente considerado como peligro español. Es un constante y permanente condicionante estructural que, no se duda, puede ser expresión de abigarrado prejuicio nacionalista portugués. Pero es evidente que era, si es que realmente se quiere ver así, un prejuicio socialmente actuante. El iberismo ha sido históricamente y, repito, históricamente, un pensamiento elitista, sin base social efectiva. Por el contrario, el nacionalismo portugués ha sido un determinante identitario que reflejaba con toda rotundidad, una comunidad imaginada en el sentido descrito por Anderson (1993). Es decir, construida social, política e históricamente por medio de un proceso de largo plazo en el que sus integrantes se perciben a sí mismos como partes de un grupo propio, cerrado y diferente a otros. 
fue vista con lógica aprensión, ya que podía pensarse que el nuevo régimen español podía animar las periódicas intentonas golpistas del monarquismo portugués o, incluso, que la monarquía española podría decidirse por una intervención en suelo luso. Pero estos temores iniciales quedaron muy pronto disipados porque el gran objetivo internacional del regeneracionismo primorriverista, más allá por supuesto de Marruecos, fue el iberoamericanismo, cuya primera piedra era el entronque efectivo con Portugal. Primo de Rivera actuó como articulador práctico de un cambio sustantivo de los planteamientos internacionalistas del nacionalismo tradicionalista y, en general, conservador español que, heredando viejos presupuestos del romanticismo decimonónico, abandonaba postulados anexionistas por una visión aliancista basada en la idea de bloques de civilización unidos más por razones espirituales que materiales. La recuperación de los valores de la tradición católica daba un nuevo contenido regenerador al conservadurismo -entendido en términos ampliosespañol y portugués haciéndolos coincidir en esa común empresa de volver a poner en pie una civilización considerada en riesgo.

Este fuerte determinismo ideológico hizo que el concepto de alianza no fuera neutro. Al contrario, aparecía como opuesto al clásico iberismo de base federalizante que desde estas concepciones se creía propio del republicanismo y, en general, de las diferentes izquierdas. La vinculación ibérica se constituía así para las derechas ibéricas (entendidas en sentido amplio) en factor de regeneración de unas naciones en decadencia por lo que ellos consideraban el efecto disolvente de las revoluciones liberal y socialista. En este sentido, no era nada nuevo, sino en realidad, una reactualización de muchas propuestas de idéntico signo y similar intención. Lo único realmente nuevo era que al calar en amplios espectros ideológicamente afines, y con capacidad para alcanzar el poder, la idea aliancista pasó a convertirse en un proyecto político realizable.

El aliancismo fue puesto en práctica por Primo de Rivera como doctrina oficial sustentadora de la política española hacia el país vecino y como parte fundamental de su proyecto americanista. El respecto a la dualidad política y la aceptación de su irreversibilidad fueron los puntos neurálgicos de una política orientada permanentemente a demostrar signos inequívocos de amistad, e incluso deseosa de alcanzar algunas realizaciones prácticas significativas. Sin embargo en Portugal, fue un discurso mucho más cuestionado dada la inveterada raíz antiespañola del nacionalismo luso. Aunque es cierto que Lisboa comenzó a aceptar una mayor intimidad con su vecino peninsular, la profundidad del contencioso iberista nunca despejó por completo el camino para una verdadera amistad peninsular. Además, el peso estructural de la Alianza Británica, esencial no sólo para la seguridad externa del país sino también como 
motor del propio proceso interno de desarrollo, impidió cualquier posibilidad de subvertir los tradicionales anclajes internacionales de Portugal.

Por eso, la política primorriverista sólo pudo alcanzar algunos éxitos parciales, aunque en una tradición de claro antagonismo, era ya mucho introducir una nueva perspectiva de complementariedad y de renuncia al enfrentamiento. La Dictadura española pudo fracasar en sus intentos de crear una verdadera alianza peninsular, pero fue decisiva para que las relaciones entre los dos países entraran en una fase de distensión e incluso para que avanzaran por sendas de cierta confianza mutua. El golpe de Estado militar en Portugal fue el tercer momento decisivo de esta evolución.

En efecto, el 28 de mayo de 1926 los militares portugueses acabaron con el gobierno del Partido Republicano. El caos administrativo y financiero de los gobiernos militares no permitió avanzar mucho por esta nueva senda de entendimiento, aunque sí lo suficiente como para elevar las legaciones diplomáticas al rango de embajadas, acto simbólico que aunque pensado antes de esa fecha, fue aprovechado para manifestar la nueva sintonía entre los regímenes militares ibéricos. Y es que el nuevo régimen lisboeta había sido acogido con evidente simpatía por Madrid, ya que el golpe permitía una convergencia política basada en una amplia empatía ideológica que sólo podía beneficiar los deseos españoles de entendimiento.

Esa convergencia y esa empatía permitieron descubrir identidades y afinidades profundas que, en realidad, aproximaban más a esas elites ibéricas entre sí, que lo que los viejos prejuicios nacionalistas las distanciaban. Cuando se amortiguó el factor de separación más fundamental, esto es, cuando aminoró la percepción de peligro español y el dualismo peninsular quedó establecido como imperativo categórico, las relaciones entre los dos países pudieron efectivamente mejorar. Por tanto, esta nueva dinámica de relación no tuvo una simple base de simpatía autoritaria, sino una base constituida por la esencial modificación del pensamiento y la política de los sectores reaccionarios y conservadores españoles hacia el país vecino. No sucedió así con las corrientes republicanas y de izquierda, que siguieron aferradas a ese iberismo federalizante que emergió después de la caída de la Dictadura de Primo de Rivera y la implantación de la Segunda República española, que hizo, de nuevo, oscilar el péndulo de la política peninsular hacia el antagonismo y el conflicto.

\section{Bibliografía}

ABREU, Luís Machado de (1996). Pendências iberistas no Oitocentismo portugués. Revista da Universidade de Aveiro-Letras, 13, 53-68.

ALARÇÃO, Jorge de (2007). Portugal um Estado não predeterminado. Revista de História das Ideias, 28, 9-15. 
ALMUNIA, César (1994). El discurso iberista entre el vacío y el recelo. En Portugal e o mundo, do passado ao presente (209-222), Cascais: Câmara Municipal.

ÁlVAREZ JUNCO, José (1994). España: el peso del estereotipo. Claves de Razón Práctica, 48, 2-10.

ANDERSON, Benedict (1993). Comunidades Imaginadas. Buenos Aires: Fondo de Cultura Económica.

ANTUNES, José Freire (2003). Os espanhóis e Portugal. Lisboa: Oficina do Libro.

ARAGÃO, Rui (1985). Portugal, o desafio nacionalista. Lisboa: Teorema.

AREILZA, José María de; CASTIELLA MAÍZ, Fernando María (1941). Reivindicaciones de España. Madrid: Instituto de Estudios Políticos.

BARCIA TRELLES, Camilo (1939). Puntos cardinales de la política internacional de España. Barcelona: Ediciones Fe.

BULLÓN Y FERNÁNDEZ, Eloy (1916). Las relaciones de España con Portugal. Enseñanzas del pasado y orientaciones para el porvenir. Madrid: Real Academia de Jurisprudencia y Legislación.

CABERO, Vicente (2002). Iberismo y cooperación. Pasado y futuro de la península ibérica. Salamanca: Universidad de Salamanca.

CABERO, Vicente; PERALTA, Beatriz (1998). La Unión Ibérica. Apuntes histórico-geográficos a mediados del siglo XIX. Boletín de la AGE, 25, 17-38.

CATROGA, Fernando (1985). Nacionalismo e ecumenismo. A questão ibérica na segunda metade do S. XIX. Cultura, Historia e Filosofía, IV, 419-463.

CHACON, Vamireh (2005). A grande Ibéria: convergencia e divergencia de uma tendencia. São Paulo: UNESP.

CHAGAS, João Pinheiro (1929-1932). Diários, 4 vols. Lisboa: Parceria António Maria Pereira. <http://purl.pt/25015/4/br-11267/br-11267_item4/br-11267_PDF/br11267_PDF_24-C-R0150/br-11267_0000_1-394_t24-C-R0150.pdf>

COMESAÑA PAZ, Alfredo (2013). 1919, Portugal en el laberinto, Tesis Doctoral inédita. Madrid: UNED.

CORDERO TORRES, José María (1944). Aspectos de la misión universal de España. Doctrina internacional y colonial de España. Madrid: Vicesecretaría de Educación Popular.

COSTA, Afonso (1977). Discursos parlamentares, 1914-1926. Amadora: Bertrand.

DURÁNTEZ PRADOS, Álvaro (2014). Paralelismos y convergencias entre la comunidad iberoamericana de naciones y la comunidad de países de lengua portuguesa: ¿existe un espacio multinacional de países de lenguas ibéricas? Málaga: Última Línea.

FERNÁNDEZ CLEMENTE, Eloy (1997). Portugal en los años veinte. Los orígenes del Estado Novo. Valladolid: Universidad de Valladolid.

FERREIRA, Paulo Bruno Rodrigues (2016). Iberismo, hispanismo e os seus contrários: Portugal e Espanha (1908-1931) Tesis Doctoral. Universidade de Lisboa. http:// repositorio.ul.pt/bitstream/10451/22974/1/ulsd072479_td_Paulo_Ferreira.pdf [consultado: 20-VI-2016]. 
GAY Y FORNER, Vicente (1915). El imperialismo y la guerra europea. Los principios nacionalistas y el iberismo. Madrid: F. Beltrán.

GODINHO, Vitorino Magalhães (2004). Portugal. A Emergência de Uma Nação. Lisboa: Colibrí.

GOMES, George Manuel (2015). A construção do «hispanismo» na obra política de António Sardinha (1915-1925). Ler História, 68, 109-127. https://doi.org/10.4000/lerhistoria.1699

HORTA, António Fernandes; DUARTE, António Paulo (1998). Portugal e o equilíbrio peninsular. Pasado, presente e futuro. Lisboa: Europa-América.

HUGUET SANTOS, Montserrat (2007). El iberismo: un proyecto de espacio público peninsular. Alcores. Revista de Historia Contemporánea, 4, 243-275.

JIMÉNEZ REDONDO, Juan Carlos (2000). La relación política luso-española. Ayer, 37, 271-286.

JIMÉNEZ REDONDO, Juan Carlos (2013a). El Mercado Común Ibérico como metáfora de una unidad imposible, 1945-1977. Historia y política: Ideas, procesos y movimientos sociales, 30, 55-88.

JIMÉNEZ REDONDO, Juan Carlos (2013b). Lusitanidad e Hispanidad: comunidad y conflicto en el imaginario comunitario de Portugal y España. En JIMÉNEZ REDONDO, Juan Carlos; SAAVEDRA INARAJA, María (eds.). Tan iguales, tan diferentes. La construcción de la identidad iberoamericana (251-349). Madrid: Encuentro.

JIMÉNEZ REDONDO, Juan Carlos; LOFF, Manuel (1998). Problemas históricos de la relación luso-española. En TORRE GÓMEZ, Hipólito de la (ed.), España y Portugal. Siglos IX-XX. Vivencias históricas (367-380). Madrid: Síntesis.

JOVER ZAMORA, José María (1981). La era isabelina y el sexenio revolucionario, 18341874. Madrid: Espasa-Calpe.

JOVER ZAMORA, José María (1986). La percepción española de los conflictos europeos. Revista de Occidente, 57, 5-42.

LAMO DE ESPINOSA, Emilio (2000). La imagen de España en el exterior. Conclusiones de una investigación. Estudios Agrosociales y Pesqueros, 189, 243-268.

<http://www.magrama.gob.es/ministerio/pags/Biblioteca/Revistas/pdf_reeap\%2 Fr189_11.pdf>

LÓPEZ-CORDÓN, María Victoria (1975). El pensamiento político-internacional del federalismo español. Barcelona: Planeta.

MARCILHACY, David $\left(2010^{a}\right)$. Raza Hispana. Hispanoamericanismo e imaginario nacional en la España de la Restauración. Madrid: CEPC.

MARCILHACY, David (2010b). La péninsule Ibérique et le Mare Nostrum atlantique: ibérisme, hispanisme et américanisme sous le règne d'Alphonse XIII de Bourbon. Revista de História das Ideias, 31, 121-154.

MARTÍN MARTÍN, Teodoro (2009). El movimiento iberista. Aproximación a la historia de una idea. ASPUR. <www.aspur.org/movimiento-iberista-libro-b.pdf>

MARTINS, Joaquim Pedro de Oliveira (1988. [1879]). Historia de la civilización ibérica. Madrid: Aguilar. 
MASCARENHAS, Manuela (1980). A questão ibérica, 1850-1870. Braga, separata de Bracara Augusta.

MATOS, Sérgio Campos (2006). Iberismo e identidade nacional (1851-1910). CLIO. Revista do Centro de História da Universidade de Lisboa, 14, 349-400.

MATOS, Sérgio Campos (2007). Conceitos de Iberismo em Portugal. Revista de História das Ideias, 28, 169-193. https://doi.org/10.14195/2183-8925_28_8

MATOS, Sérgio Campos (2008). Consciência histórica e nacionalismo (Portugal, séculos XIX-XX). Lisboa: Livros Horizonte.

MATTOSO, José (1985). Identificação de um pais. Ensaio sobre as origens de Portugal, 1096-1325. Lisboa: Estampa. 2 vols.

MATTOSO, José (1998). A identidade nacional. Lisboa: Fundação Mário Soares/ Gradiva.

MEDEIROS FERREIRA, José (1988). Un seculo de problemas. As relações luso-espanholas da União Ibérica à Comunidade Europeia. Lisboa: Livros Horizonte.

MOLiNA, César Antonio (1990). Sobre el iberismo y oros escritos de literatura portuguesa. Barcelona: Akal.

NIDO Y SEGALERVA, Juan del (1914). La Unión Ibérica: estudio crítico, histórico de este problema. Madrid: Tipografías de Prudencio P. de Velasco.

NIDO Y SEGALERVA, Juan del (1915). La Unión Ibérica: Opúsculo. Mi contestación a la prensa lusitana. Madrid: Ramona Velasco.

OLIVEIRA, César (1985). Portugal e a II República de Espanha (1931-1936). Lisboa: Perspectivas \& Realidades.

OLIVEIRA, César (1995). Cem anos nas relações luso-espanholas. Politica e economía. Lisboa: Cosmos.

PABÓN, Jesús (1945). La Revolución Portuguesa, de Sidónio Pais a Salazar. Madrid: Espasa-Calpe.

PENA RODRÍGUEZ, Alberto (1998). El gran aliado de Franco: Portugal y la guerra civil española: prensa, radio, cine y propaganda. Sada: Ediciós do Castro.

PEREIRA, Maria da Conceição Meireles (1996). Concertação económica peninsular e união aduaneira na imprensa portuense. Revista da Faculdade de Letras. Historia, 13, 423-462.

PEREIRA, Maria Conceição Meireles (2010). Iberismo e nacionalismo em Portugal. Da Regeneração à República. Entre Utopia e Distopia. Revista de História das Ideias, 31, 257-285. https://doi.org/10.14195/2183-8925_31_10

PÉREZ DE ANDREU, Juan (1924). El iberismo como base de una expansión soñada, s.l.: s.e.

PÉREZ ISASI, Santiago (2014). Literatura, iberismo(s), nacionalismo(s): Apuntes para una historia del iberismo literario (1868-1936). Revista electrónica de teoría de la literatura y literatura comparada, 11, 64-79, <http://www.452f.com/pdf/numero11/11_452f-mono-santiago-perez-isasiorgnl.pdf> 
PIMENTA, Alfredo (1935 [1934]). Elementos de Historia de Portugal. Lisboa: Empresa Nacional de Publicidade.

QUINTANAR, Fernando Gallego de Chaves y Calleja, marques de (1920). Portugal y el hispanismo. Madrid: s.e.

RINA, César (2012). Reflexiones historiográficas en torno al Iberismo. En IÑESTA MENA, Félix; MATEOS SACÍBAR, Francisco J. (coords.). España: Nación y Constitución y otros estudios sobre Extremadura (187-195). Llerena: Sociedad Extremeña de Historia.

RIVERO, Ángel (2010). España, Portugal y los falsos amigos. Relaciones Internacionales, 13. <www.relacionesinternacionales.info.relación>

ROCAMORA ROCAMORA, José Antonio (1989). Un nacionalismo fracasado: el iberismo. Espacio, Tiempo y Forma, Serie V, Historia Contemporánea, 2, 29-56.

ROCAMORA ROCAMORA, José Antonio (1994). El nacionalismo ibérico. Valladolid: Universidad de Valladolid.

RODRÍGUEZ ESTEBAN, José Antonio (1998). Geopolitical perspectives in Spain: from the Iberismo of the 19th century to the Hispanoamericanismo of the $20^{\text {th }}$. Finisterra, XXXIII, 185-193.

RUDEL Christian (1968). Le Portugal et Salazar. Paris: Les Editions Ouvrières.

RUEDA, Germán (1998). El iberismo del siglo XIX. Historia de la posibilidad de unión hispano-portuguesa. En TORRE GÓMEZ, Hipólito de la; VICENTE, António Pedro (dirs.). España-Portugal. Estudios de historia contemporánea (181-214), Madrid: Editorial Complutense.

SALAZAR, António de Oliveira (1945). Portugal e la paz. Lisboa: SNI.

SÁNCHEZ CERVELLÓ, Josep (1998). El nacionalismo portugués. En Los 98 ibéricos y el mar. El Estado y la política. Vol. 3 (235-254). Lisboa: Sociedad Estatal Expo98.

SANTOS, Miguel Dias (2011). A contra-Revolução na I República, 1910-1919. Coimbra: Universidade de Coimbra.

SARAMAGO, José (1990). Mi iberismo. Prólogo a MOLINA, César Antonio. Sobre el iberismo y oros escritos de literatura portuguesa. Barcelona: Akal.

SARDICA, José Miguel (2013). Ibéria. A Relação entre Portugal e Espanha no século XX. Lisboa: Aletheia.

SARDINHA, António (1930 [1924]). La Alianza Peninsular. Madrid: Imprenta Sáez Hermanos.

SEPÚlVEDA, Isidro (2005). El sueño de la Madre Patria. Hispanoamericanismo y nacionalismo. Madrid: Marcial Pons Historia y Fundación Carolina.

SOBRAL, José Manuel (2002). La formación de la identidad nacional portuguesa como proceso histórico. Historia y Política, 7, 55-82.

TELO, António José; TORRE GÓMEZ, Hipólito de la (2000). Portugal e Espanha nos sistemas internacionais contemporáneos. Lisboa: Cosmos.

TORRE GÓMEZ, Hipólito de la (1982). Portugal, un nacionalismo antiespañol. Revista de Occidente, 17, 86-93.

TORRE GÓMEZ, Hipólito de la (1983). Antagonismo y fractura peninsular. España-Portugal, 1910-1919. Madrid: Espasa-Calpe. 
TORRE GÓMEZ, Hipólito de la (1984). Del "peligro español” a la amistad peninsular. España-Portugal, 1919-1930. Madrid: UNED.

TORRE GÓMEZ, Hipólito de la (1988). La relación peninsular en la antecámara de la Guerra Civil Española. Mérida: UNED.

TORRE GÓMEZ, Hipólito de la (2002). El imperio del Rey. Alfonso XIII, Portugal y los ingleses, 1907-1916. Mérida: Editora Regional de Extremadura.

TORRE GÓMEZ, Hipólito de la (2005). España y la identidad portuguesa. Una reflexión histórica. En PALACIO ATARD, Vicente (ed.). De Hispania a España: el nombre y el concepto a través de los siglos (197-215). Madrid: Temas de Hoy.

TORRE GÓMEZ, Hipólito de la (2013). Iberismo y relaciones peninsulares en la época contemporánea. En MORALES MOYA, Antonio; FUSI AIZPURÚA, Juan Pablo; BLAS GUERRERO, Andrés de (coords.). Historia de la nación y del nacionalismo español (338-346). Madrid: Galaxia Gutemberg.

TORRE GÓMEZ, Hipólito de la; SÁNCHEZ CERVELLÓ, Josep (2000). Portugal en la edad contemporánea. Madrid: UNED.

VÁZQUEZ CUESTA, Pilar (1975). A Espanha ante o "Ultimátum". Lisboa: Horizonte.

VAZQUEZ DE MELLA Y FANJUL, Juan (1915). El ideal de España. Los tres dogmas nacionales. Madrid: Imprenta alemana.

VELARDE FUENTES, Juan (1985). El pensamiento económico peninsular en relación con la Unión Ibérica. Anales de la Real Academia de Ciencias Morales y Políticas, 62, 233-264.

VELARDE FUENTES, Juan (2002). Desencuentros y encuentro de las economías portuguesa y española. Revista Asturiana de Economía-RAE, 25. <http://www.revistaasturianadeeconomia.org/raepdf/25/P297-328.pdf>

VERGARA, Máximo (1925). Por la España grande, la unidad de la raza hispana. Madrid: Editorial Reus. 